\title{
Analysis of photovoltaic Cell Arrangement in the Independent solar Power generating System Installed above Farm Land
}

\author{
Gezhiwu $^{1, a}$, Zhouyu ${ }^{2, b}$ \\ ${ }^{1}$ No.99 South Longkun Road, Hainan normal university, Haikou city, Hainan province, China \\ ${ }^{2}$ North Campus, Hainan normal university, Haikou city, Hainan province, China \\ aHainanedc@163.com, bford33@163.com
}

Keywords: Photovoltaic panels, Farm land, Arrangement

\begin{abstract}
In order to break through the bottleneck of solar photovoltaic power generation, and off-season vegetables' problems in Hainan island', to arrange photovoltaic facilities above farm land generate electricity was suitable. By using novel and ingenious arrangement on panels, we can make farmland temperature distribution more uniform, decrease temperature differences between shading and lighting area significantly, also reduce wind resistance significantly. The system was suitable for general farmers to implement in hot climate area for example in Hainan island in China. By using this system, famers can produce cops and electricity at the same time and get double income.
\end{abstract}

\section{Introduction}

There are abundant solar energy resources with wide distribution in Hainan, China. At present, the technology of solar photovoltaic power is becoming more and more mature, which has become one of the most suitable and renewable energy technologies. However, the energy density distribution of sunshine is small, but on the contrary, solar power needs taking up large area. Nowadays, most of the battery plates using for solar power are installed on the exclusive field, and they take up a large number of land resources, which makes the cost higher and its promotion of using extremely restricted. This problem seems to be prominent on this land-scare international tourism island, and it has become the bottleneck problem that restricts the development of solar power in Hainan island.

Another problem in Hainan island or in the tropics is abnormal dull season with the vegetables.

The climate in Hainan's winter is mild and the temperature is quite suitable, besides, there's adequate illumination, which are all good for the growth of different kinds of crops. So Hainan is called the natural greenhouse. However, summer is long and the glare of sunlight there is very intense, in addition, the typhoon and rainstorms are really frequent. All of the reasons above are hardly conducive to the normal growth of crops and vegetables. Therefore there is a totally different dull season from areas in our country. The summer usually lasts nine months which begins from March and ends in November in Hainan. From March to June, the solar altitude angle is large and the thunderstorm season has not yet begun, so the temperature is really high. This period is of high-temperature, strong sunlight, low humidity, with the dry and hot wind prevailing. In addition, scarce precipitation leads to severe drought, which does harm to sowing and growth of vegetables. There are a lot of typhoons which lasts long time, so typhoon becomes one of the agricultural disasters in Hainan. There is frequent and intense typhoon in Hainan. According to the statistics, Hainan sees 7.9 times typhoons on average each year, including 2.6 times that make directly landfall in Hainan. There are three times typhoons with above eight level in SanYa each year. The typhoon brings heavy rain, sometimes the daily maximum precipitation reaches 545.3 millimeter. Hainan tends to be influenced by typhoon from May to December, especially in July to October. Accompanied by heavy rain, typhoons have devastating effects on crops and vegetables. At the same time, typhoons could lead to flood disaster. Besides, it's very negative for the growth of vegetables.

The development of horticultural facilities does not have a fixed pattern, it depends on some factors just like the environmental condition, the level of economy, the way of operation and so on. Among the 
above, the natural condition plays a decisive role. As mentioned above, the main reason that causes the dull season of vegetables in Hainan is dry and hot weather, high temperature, strong sunlight, and frequent rainstorms and typhoons. To overcome these negative factors, it should focus on shading, cooling and protection against the wind and rain. To be sure, it's unsuitable for Hainan to vigorously develop horticultural facilities which focus on insulation like the north part of China.

For general vegetable crops including fond light vegetables, light saturation point is not more than 3 50000 lx, but light intensity in summer in Hainan province generally $10 \sim 120000 \mathrm{~lx}$, accompanied by 35 a $38{ }^{\circ} \mathrm{C}$ high temperature. Therefore, in the hot summer, high temperature and intense light often cause plant chlorophyll damage and metabolic disorder, which affects the normal crop growth and development.

The summer cultivation dominated by sun shading net and rainproof shed meet the above requirements well and fulfill the task to produce and supply the vegetables and fruits for the whole year, which should be the main direction in the future for Hainan. In order to reduce the influence of the climate of summer and autumn on vegetables production, it's a kind of feasible measures to design and make application of shade greenhouse in tropic. To arrange the solar photovoltaic panels and slar cells on the panels properly above farmland can solve the problems mentioned above.

\section{Arrangement of photovoltaic panels}

Arrangement of photovoltaic panels is show as follow in Fig.1 to Fig.3.

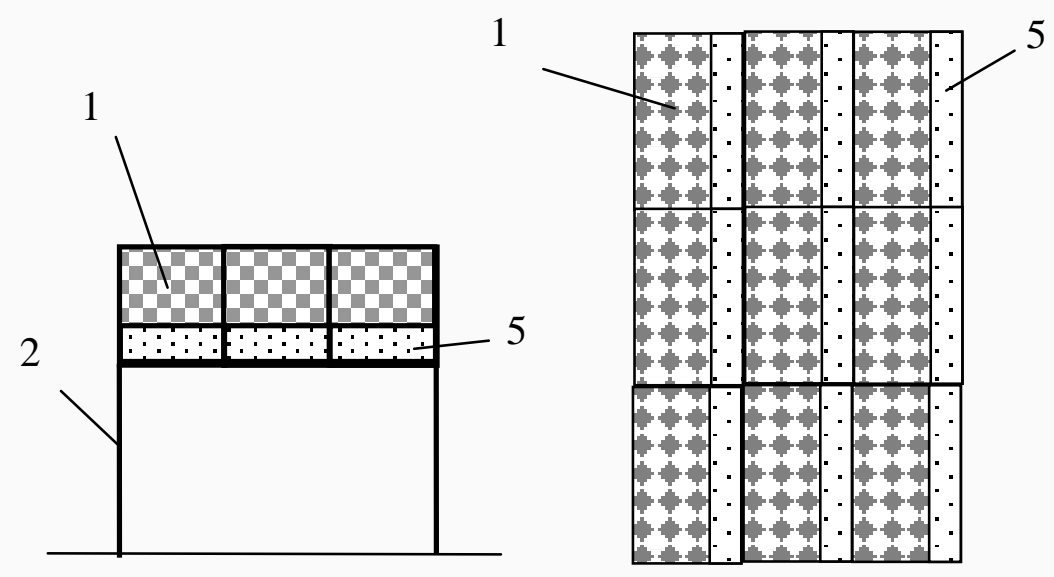

Fig.1, Left view
Fig.2 Vertical view

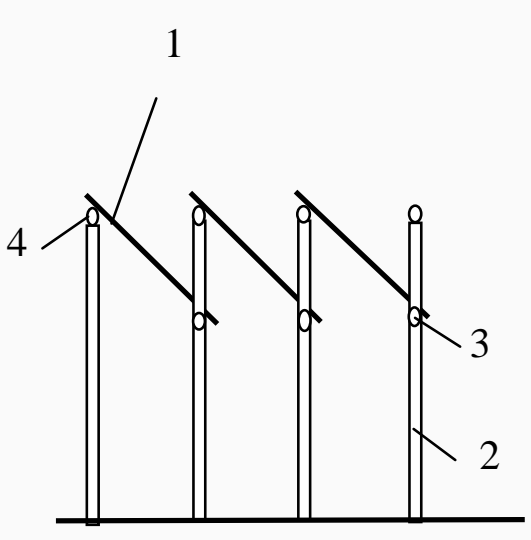

Fig.3, left view

Figure 1 is main view or front view, figure 2 is the vertical view, figure 3 is the left view. Solar cells 1 were arranged above transparent panels 5, there are some uniformly distributed small holes on transparent panels 5. Solar panels 1 were arranged on low beam 3 and high beam 4 which fixed on column 2 , the position of low beam 3 fixed on column 2 can be adjusted, so the solar panels can be tilted towards the south. For the panels 5 being transparent and with some small hole, crops below can enjoy proper sunlight, wind and raindrops, so can thrive well.

\section{Arrangement of photovoltaic cells on panels}

The arrangement of photovoltaic cells on panels of popular double glass components now show as in Figure4 and 5. 


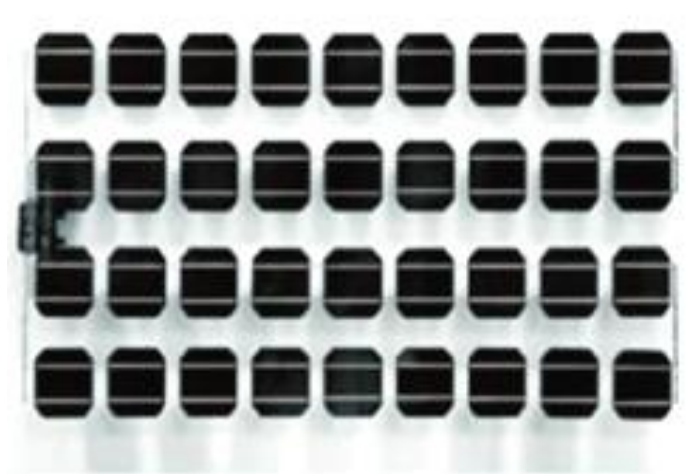

Fig.4, Double glass components

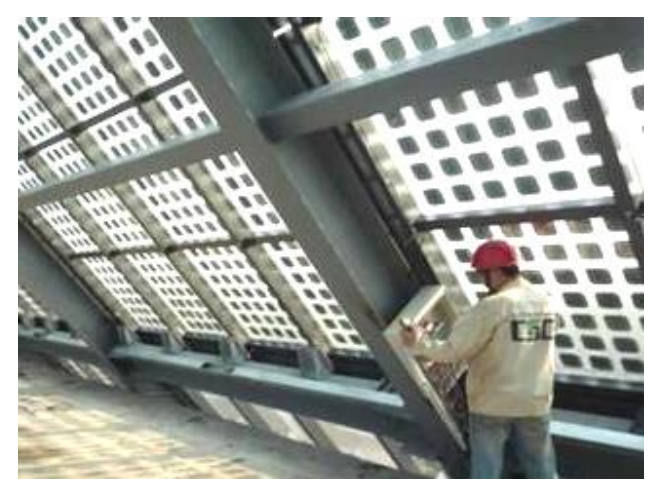

Fig.5, Double glass components roof

The arrangement of photovoltaic cells on panels above in Fig.4 and Fig.5 are suitable to be used as the wall of building or roof of common building, but are not suitable to be used to shade sunlight above farmland. According to our study, the best arrangement of photovoltaic cells on panels used to shade sunlight above farmland are as follows in Fig.6 and Fig.7.

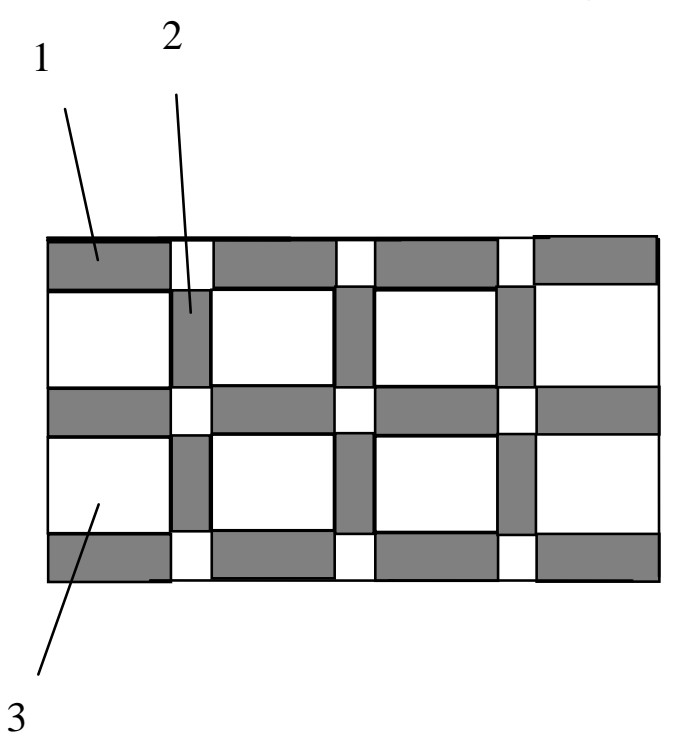

Fig.6 Arrangement I of photovoltaic cells

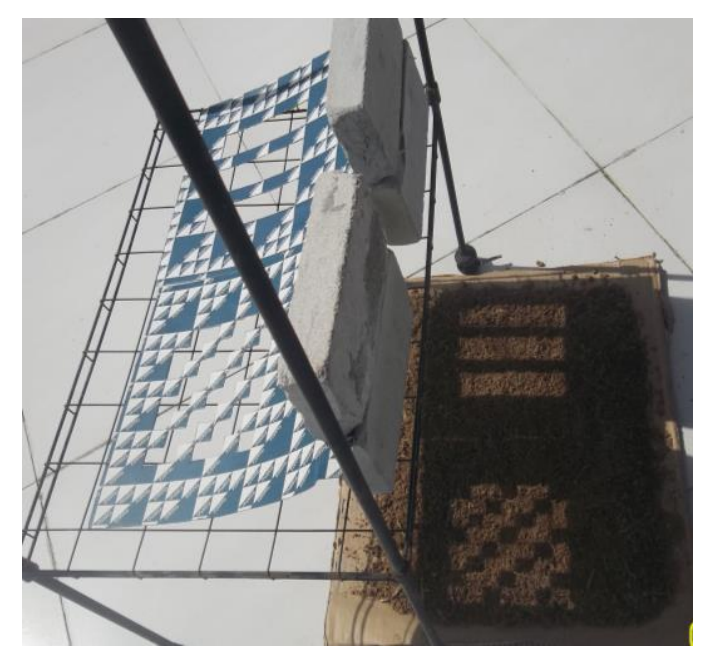

Fig. 8, Analog Experiment

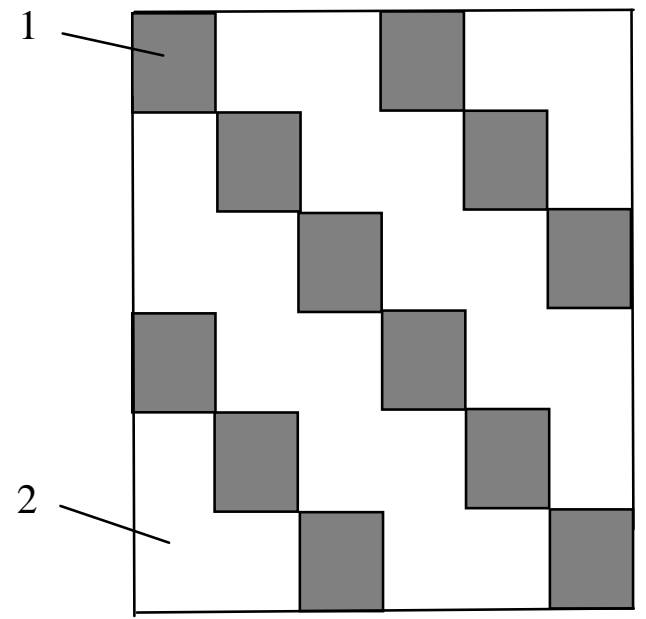

Fig.7 Arrangement II of photovoltaic cells

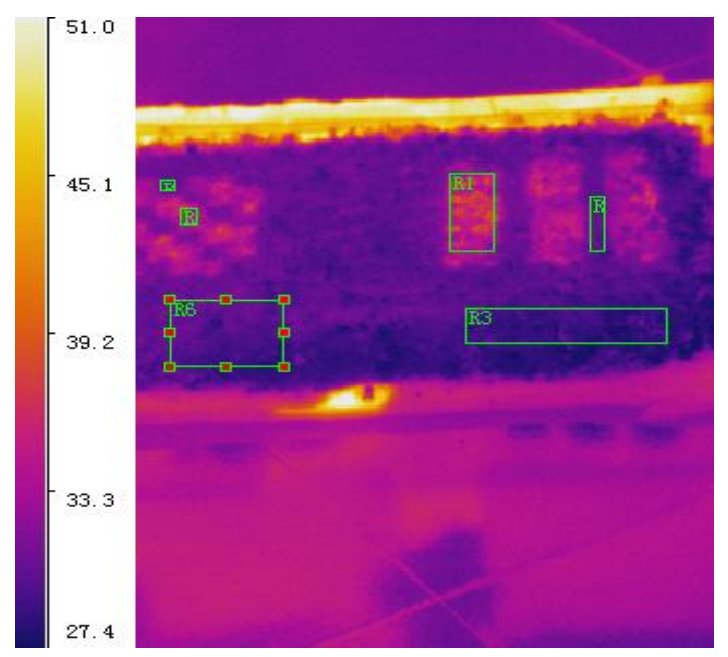

Fig.9, The infrared thermal Imaging 
Table 1, Experimen resuls analysis

\begin{tabular}{|l|l|l|l|}
\hline Label & Maximum & Minimum & Average \\
\hline R1 & $38.9^{\circ} \mathrm{C}$ & $31.9^{\circ} \mathrm{C}$ & $35.7^{\circ} \mathrm{C}$ \\
\hline R2 & $31.5^{\circ} \mathrm{C}$ & $29.7^{\circ} \mathrm{C}$ & $30.9^{\circ} \mathrm{C}$ \\
\hline R3 & $30.7^{\circ} \mathrm{C}$ & $27.7^{\circ} \mathrm{C}$ & $29.0^{\circ} \mathrm{C}$ \\
\hline R4 & $37.0^{\circ} \mathrm{C}$ & $33.4^{\circ} \mathrm{C}$ & $35.0^{\circ} \mathrm{C}$ \\
\hline R5 & $31.5^{\circ} \mathrm{C}$ & $30.8^{\circ} \mathrm{C}$ & $31.2^{\circ} \mathrm{C}$ \\
\hline R6 & $31.6^{\circ} \mathrm{C}$ & $28.1^{\circ} \mathrm{C}$ & $30.0^{\circ} \mathrm{C}$ \\
\hline
\end{tabular}

Using the arrangement as in Fig. 6 and Fig.7, the farmland temperature distribution become more uniform, temperature differences between shading and lighting areas were decreased significantly.

Experiment did in Haikou city in Hainan inland showed that temperature differences can reduce more than $3{ }^{\circ} \mathrm{C}$ compared with that of the as general arrangements of photovoltaic cells show in Fig. 4 and Fig.5, we can perforate some holes on panels .

By doing this, crops below can enjoy proper sunlight, wind and raindrops, so can thrive well. What's more, this arrangement can reduce wind resistance observably, so we use simple and slim structure Support the panels at low cost.

Through the experiment to compare the temperature differences between different photovoltaic cells arrangements, we got the result as follows.Fig. 8 shows the experiment scene to analog panel arrays shading effect in the surface soil, The infrared thermal imaging results shows in Fig.9.

\section{Summary}

The best arrangement of photovoltaic cells on panels used to shade sunlight above farmland disclosed in this paper and can make farmland temperature distribution more uniform, decrease temperature differences between shading and lighting area significantly, also reduce wind resistance significantly,

the system was suitable for general farmers to implement in hot climate area for example in Hainan island in China. By using this system, famers can produce cops and electricity at the same time and get double income.

\section{Acknowledgement}

This research was financially supported by the Physics Science priority Foundation of Hainan normal university, and was also supported by the Solar Energy Laboratory of Hainan normal university, and The institute of Vegetables in Hainan province Academy of agricultural Sciences.

\section{References}

[1] Xie Deliang, Japanese Famers cultivate vegetables and Electricity at the same time, environment and life, December 2013.pp.68-69.

[2] QianXun, Japanese Famers cultivate vegetables and Electricity at the same time, Agricultural market weekly, May 2014.pp.62-63.

[3] XiaoRixin, Fundamental Types Facility Cultivation and Main Facility Cultivation Techniques in Hainan, Tropical agricultural engineering,Hainnan, Vlol.34,No.1,Feb.2010,pp.56-65.

[4] GeZhiwu, China. Patent 201420489433.3.

[5] GeZhiwu, China. Patent 201410430562.X.

[6] Information on http://china.risenenergy.com/aboutus.htm.

[7] Information on http://www.youboy.com/pics77480642.html.

[8] Information on http://nn.wenming.cn/xqdt/201403/t20140325_1078029.html. 